\title{
Corpos que Caem: Adolescência, Prisão e Psicanálise
}

\author{
Adriele Cardoso Sussuarana ${ }^{1}$ \\ Alba Caroline Tavares dos Santos ${ }^{2}$ \\ Aleson Hernan Morais dos Santos ${ }^{3}$
}

\section{Resumo}

Objetiva-se através desse trabalho expor de forma breve o relato de experiência de uma intervenção grupal realizada durante dois meses em 2017 com adolescentes que cumprem medidas socioeducativas e se encontram em situação de privação de liberdade na cidade de Macapá-AP. Indica-se que tais adolescentes não se adequavam com facilidade as atividades propostas pela instituição. No espaço destinado à palavra, era o espaço-tempo do corpo que os protagoniza. A partir desse endereçamento específico, agitação corporal, elaborou-se uma intervenção através de exercícios de expressão corporal com o objetivo de possibilitar um dispositivo clínico de escuta. Enfatiza-se que não reduzir a psicanálise ao espaço clínico do consultório pressupõe elaborar ações que a utilizem como referencial ético e teórico no campo social. Além de histórias fragmentadas por vivências traumáticas, foi possível observar a manifestação do circuito da compulsão à repetição e da pulsão de morte na condição de encarceramento e aprisionamento social que atravessam os adolescentes.

PALAVRAS-CHAVE: Pulsão de morte. Prisão. Adolescência. Corpo.

\footnotetext{
1 Psicóloga na Secretaria de Saúde do Estado do Amapá (2013-2018). Psicanalista em formação pelo CPPA, Círculo Psicanalítico do Pará filiado ao CBP, Círculo Brasileiro de Psicanálise (2013). Av. Piauí, 525, Pacoval, Macapá, Brasil. adrielesussuarana@gmail.com

2 Psicóloga voluntária na Secretaria de Saúde do Estado do Amapá (2015-2017). Estuda psicanálise no Fórum do Campo Lacaniano FCL-SP (2018). Rua São Vitório, 286, Vila Nhocuné, São Paulo, Brasil. albacaroline09@gmail.com.

${ }^{3}$ Psicólogo voluntário na Secretaria de Saúde do Estado do Amapá (2015-2017). Av. Desidério Antônio Coelho, 701, Centro, Macapá, Brasil. alesonhernan@live.com
} 


\section{INTRODUÇÃO}

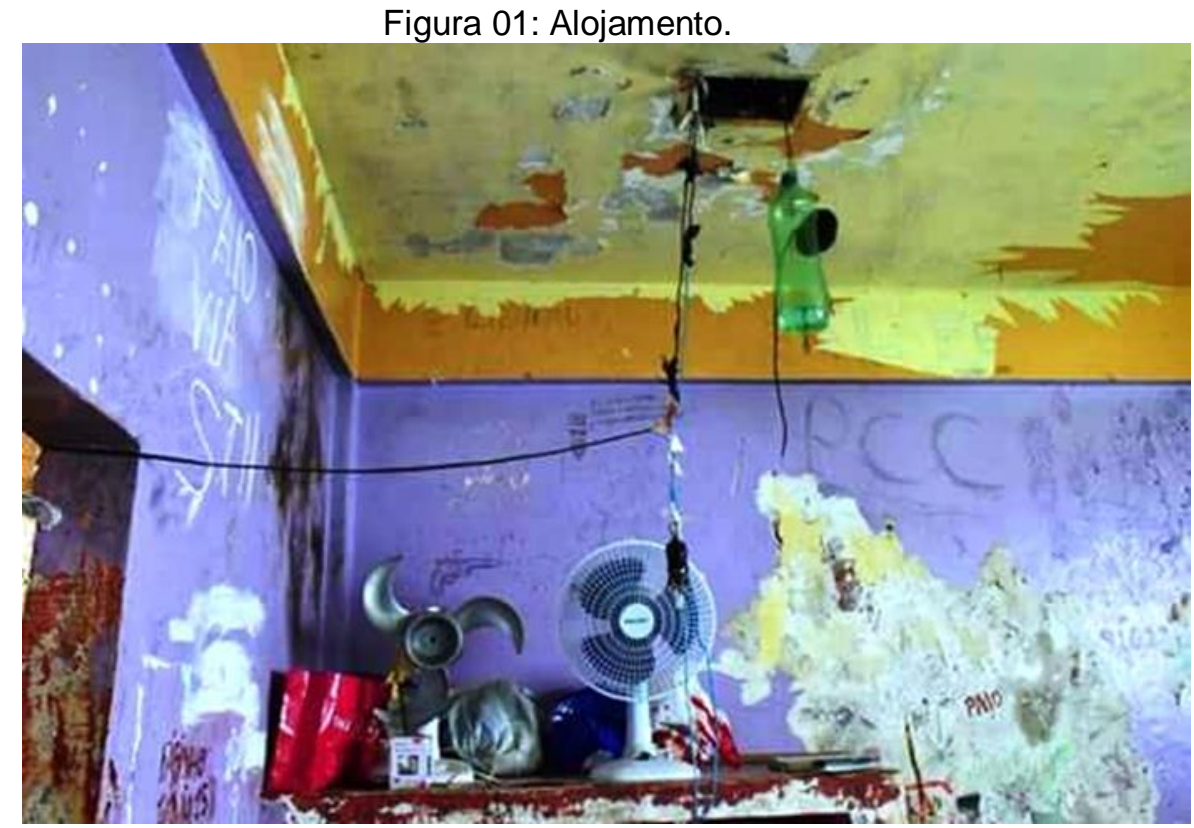

Fonte: Site jornalístico Seles Nafes (Disponível em: https://selesnafes.com/2018/02/). Foto: Tribunal de Justiça do Amapá

[...] E em breve tinha dentro da sala uma gaiola com os ossos de um sagui devorado por si mesmo. Um pequeno estômago repleto de si mesmo (ABREU, 1977, p. 88)

Esse trabalho pretende analisar a partir da perspectiva psicanalítica uma breve intervenção grupal realizada com adolescentes que cumprem medidas socioeducativas1 e se encontram institucionalizados em situação de privação de liberdade. Tais adolescentes não se adequam com facilidade as atividades propostas pela instituição, mesmo em contextos grupais há momentos em que apresentam agitação psicomotora, não toleram o tempo de espera da fala do outro para se manifestar, se contorcem na cadeira, levantam, saem e entram várias vezes da sala de grupo. De acordo com a equipe técnica: "Eles são muito agitados, não são colaborativos e tentam sabotar todas as iniciativas de grupos de apoio, dificilmente participam de uma atividade do início ao fim".

No espaço destinado à palavra, era o espaço-tempo do corpo que os protagonizava. A partir desse endereçamento específico - a agitação corporal elaborou-se uma intervenção que iniciava através de exercícios de sensibilização dos órgãos do sentido (olhar, tato, audição, olfato), bem como exercícios de expressão corporal propostos por Boal (1979), Spolin (1963) e Lowen e Lowen (1985). As atividades finalizavam em um segundo momento, no espaço destinado para falar sobre tais experiências.

Psicanálise \& Barroco em revista | v.16, n. 01 | julho de 2018 
Maurano (2006) enfatiza a necessidade de não reduzir a psicanálise ao espaço clínico do consultório, mas utilizá-la para contribuir com um referencial ético e teórico nas diversas ações que podem ser articuladas no campo social. Se os modos através dos quais esses sujeitos se relacionam com o mundo e estabelecem laços sociais não são convencionais, como pressupor que a escuta convencional e individual do exercício da clínica psicanalítica os alcançaria de forma efetiva nesses contextos? Foi necessário articular um método diferenciado para possibilitar um dispositivo clínico de escuta.

Os encontros foram realizados durante dois meses, duas vezes na semana durante duas horas. Participaram da intervenção dez adolescentes da instituição. $O$ instrumento que garantiu o registro das atividades, dos diálogos e atravessamentos dos facilitadores foi o diário de campo. Utilizou-se ainda o Termo de Consentimento Livre e Esclarecido (TCLE), o Termo de Autorização Institucional (TAI), bem como os princípios e normas inerentes à pesquisa com seres humanos em conformidade com a Resolução n 4.66/12, Conselho Nacional de Saúde.

Inicia-se ainda sem música, até que um dos adolescentes solicita: "Põe a música antes de começar". Ritmos fortes, tambores e percussão. A música vibra, os corpos também. Todos rodam com velocidade. Vinte mãos apertadas. Um único círculo. As mãos esticam, seguram com tanta força que machucam os dedos, os punhos. Alguns caem no chão ainda com os braços e o círculo esticado. Risos. Levantam em velocidade, retornam ao círculo, giram. Caem no chão. Risos. Braços esticados, dedos machucados. A cena se repete uma, duas, três, várias vezes.

Lacan (1964, p. 163) sobre a pulsão assevera [...] É, se posso me exprimir assim, que ela não tem dia nem noite, não tem primavera nem outono, que ela não tem subida nem descida. É uma força constante". Freud (1915, p. 148) define a pulsão como "o conceito-limite entre o psíquico e o somático". Lacan (1964) e Garcia-roza (1995) indicam ainda que, por ser parcial, o percurso pulsional possui um caráter circular. O vaivém, retorno em circuito (Verkehrung), torna-se alvo da pulsão por consequência de sua impossibilidade de satisfação definitiva. 
Reencontramos aqui o que já Ihes indiquei, isto é, que o inconsciente é o discurso do Outro [...] O discurso do circuito no qual estou integrado. Sou um dos seus elos. É o discurso do meu pai, por exemplo, na medida em que meu pai cometeu faltas as quais estou absolutamente condenado a reproduzir [...]. Estou condenado a reproduzi-las porque é preciso que eu retome o discurso que ele me legou, não só porque sou o filho dele, mas porque não se para a cadeia do discurso, e porque estou justamente encarregado de transmiti-lo em sua forma aberrante a outrem. Tenho de colocar a outrem o problema de uma situação vital onde existem todas as probabilidades que ele também venha a tropeçar, de forma que este discurso efetua um pequeno circuito no qual se acham presos uma família inteira, um bando inteiro, uma facção inteira, uma nação inteira ou a metade do globo. Forma circular de uma fala, que está justo no limite do sentido e do não sentido, que é problemática (Lacan, 1954-55, P. 127).

A impossibilidade de satisfação definitiva da pulsão coloca em relevo o vai e vêm pulsional, tendo em vista que a pulsão nunca deixa de ser uma força constante. A pulsão desenha e aprisiona em circuito os tropeços da satisfação emoldurando as vicissitudes da vida psíquica do sujeito. O esboço dessa forma circular pode ser observado em várias cenas das intervenções aqui descritas.

\section{A Escuta do ABISmo}

Os adolescentes apresentavam corpos enrijecidos com movimentos repetitivos sem nenhum tipo de deslizamento entre corpo-música. Nos momentos iniciais as formações circulares não perduravam por muito tempo, era comum um, depois outro, escorrer para as bordas, os extremos da sala de grupo. Tratava-se de uma posição para a qual eles sempre retornavam: a borda, o extremo, o limite, quando não estavam para além do círculo, fora. A sensação era a de escuta de um abismo.

Realizou-se um exercício para estimular a confiança grupal. Faz-se um círculo e o sujeito que está no centro precisa deixar o corpo à deriva de modo que os que estão ao seu entorno não o deixem cair no chão. Nesse primeiro momento, os que ficavam no centro, caíam. Uma, duas, três, várias vezes. Os corpos não se seguravam, os contornos não se sustentavam.

Que resto cai senão o objeto a? Para Lacan (1964), longe de configurar a origem, o objeto a é o objeto eternamente faltante, o único modo de satisfazer a pulsão é contornando-o. Trata-se da presença de um cavo, de um vazio ocupável por não importa que objeto e o conhecemos a partir da instância de objeto perdido, a minúsculo. Brandão Carreira (2014) indica que a inserção do sujeito na dimensão falante através do recalque originário produz um resto, um lastro que possui secreta afinidade com a repetição, o objeto a. Em sua vertente de lixo, dejeto, trata-se de um resto que sugere algo do real como um marco da origem do sujeito.

Psicanálise \& Barroco em revista | v.16, n. 01 | julho de 2018 
Sem rede de apoio ou contorno simbólico, os adolescentes eram encapsulados por corpos que se deixavam cair, identificações que se construíram a partir de um possível resto que cai. Registrou-se tal enunciação. Em momentos posteriores era recorrente a verbalização de variados relatos que remetiam ao mesmo exercício de queda sem contorno. Seja quando retratavam o picho, ato de ser marcado pela polícia e posteriormente assassinado, seja quando retratavam o mofo, que significava a deterioração e inadequação das instalações em que se encontravam alojados, bem como o tempo de espera para finalmente sair da instituição.

O exercício seguinte foi realizado novamente a partir de divisão de duplas. Cada adolescente deveria sentar em frente a sua dupla e tentar segurar o olhar do outro. Exercício simples e difícil. Enfatiza-se a expressão de ameaça de um dos jovens para o outro participante. Com uma das sobrancelhas arqueadas e o pescoço levemente flexionado, ele olhava fixamente para o outro à sua frente. Uma facilitadora tocou o seu rosto e solicitou que ele relaxasse. Ele perguntou: "Qual é a tua fita?". Em outro momento: "É tu que é a líder?". De novo: "Por onde tu mora? Já te vi por aí, moro naquelas bandas, cuidado!".

No final do encontro seguinte, um deles pediu sorrindo para que a facilitadora o levasse para casa. Que "cuidado" afinal situa-se aqui? Risco, perigo ou afeto, acolhimento? Pode-se pressupor o amor e o ódio desenhando-se na "fita" transferencial. Freud (1920) relata que a mesma oposição existente entre pulsão de vida e pulsão de morte compreende a polaridade entre amor e ódio ou ternura e agressão. São tão opostas que ao relacionar ambas, desvela-se, no entanto, que uma deriva da outra.

Fez-se um círculo no silêncio, todos se colocaram muito próximos. Receio em encostar os joelhos e os braços no outro. Indicou-se: "Podem fechar mais o círculo, não tem problema nos encostarmos". Desconforto. Poucos seguravam o olhar. Além da dificuldade no manejo do grupo, os encontros iniciais eram permeados pela falta de um repertório de fala espontâneo. As falas com frequência apresentavam-se monossilábicas e padronizadas. Assim como os cortes de cabelo, a forma como se sentavam e os olhos baixos. 


\section{O Traço do Picho no CORPO}

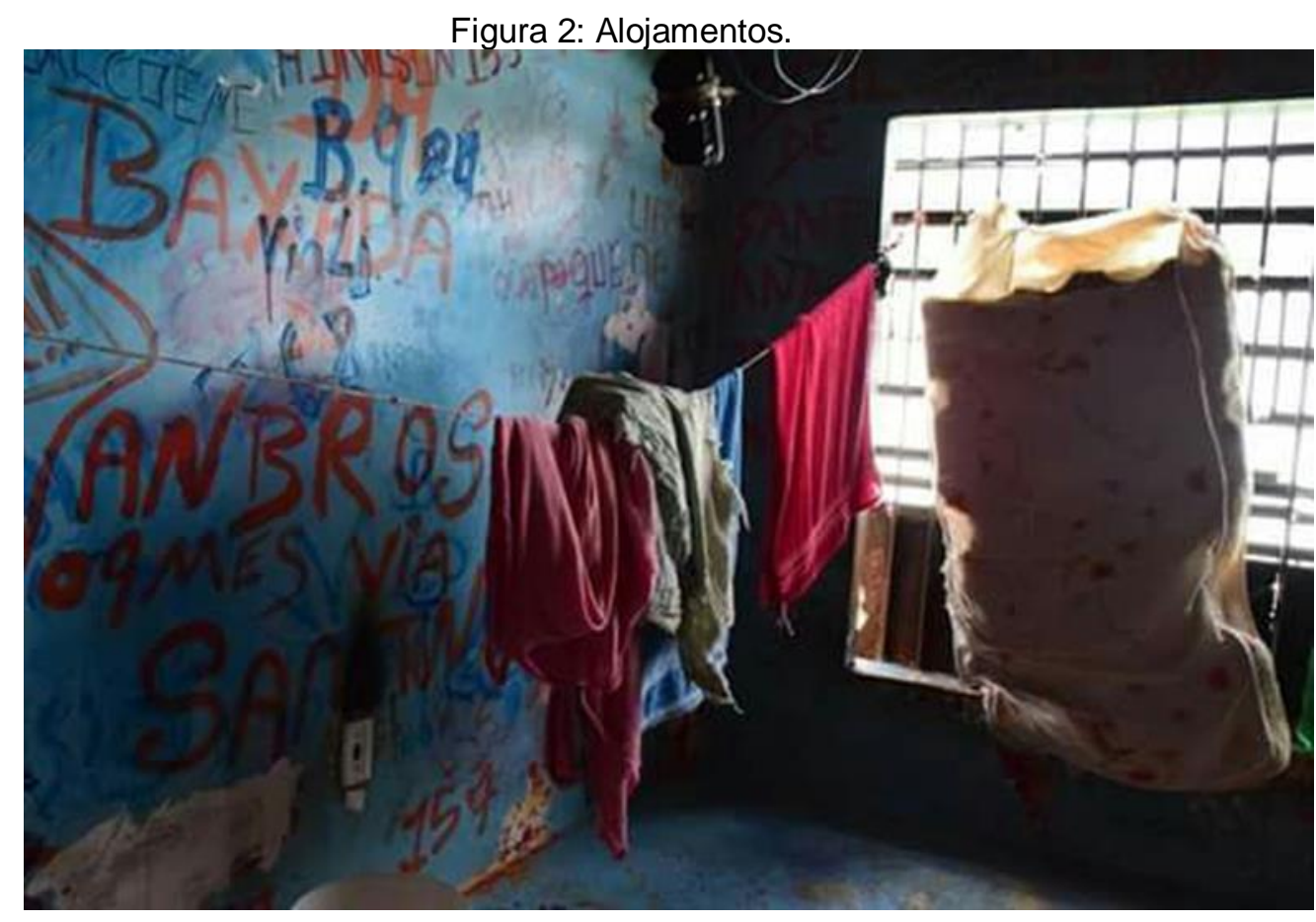

Fonte: Site jornalístico Seles Nafes (Disponível em: https://selesnafes.com/2018/02/). Foto: Tribunal de Justiça do Amapá

Duplas se espalham pela sala. O comando é simples: enquanto um corpo deitase de peito para o chão, o outro o toca e tenta aliviar as possíveis tensões das costas. Diversas reações ao exercício proposto: corpo que não aceita o toque do outro, possivelmente também por se tratar do toque de outro homem. Corpo enrijecido, mas que relaxa e aceita ser tocado pelo outro. Corpo que não sabe como tocar o outro e seu toque precisa ser conduzido pelas mãos de uma das facilitadoras. Aos poucos, os que estão deitados no chão são colocados no colo de sua dupla, aquele que exerceu o toque, devendo ali permanecer por algum tempo. Sobre esse exercício G. que o realizou em dupla com J. diz: "Lembrei de como eu ficava no colo da minha velha".

Em dado momento, os adolescentes discorrem sobre os amigos que já foram assassinados pela polícia e sobre o cuidado que precisam ter para não serem capturados, para não ficarem pichados. J. ri e diz: "Não pode ficar pichado. Ficou pichado, já era". Ficar "pichado" é sinônimo de ser identificado/marcado e posteriormente assassinado pela polícia. Denota-se aqui um sujeito que precisa correr para não ser morto, que é facilmente capturado, inscrito pelo traço do picho, inscrição não apenas da instituição polícia, mas da sociedade. 
Abriu-se espaço para falar de forma aberta sobre drogas, tendo em vista que um dos participantes estava visivelmente sob efeito de substâncias psicoativas. No entanto, a abertura oportunizou também falar sobre outras questões acerca da realidade que enfrentavam. $N$. fala sobre a superlotação, em celas que deveriam ficar dois adolescentes, encontram-se cinco ou mais. As paredes e os colchões mofados, a comida sempre em péssimas condições.

R. Indicou: "Os educadores abrem o portão para o BOPE bater na gente. Já apanhei durante duas horas e depois me deixaram ajoelhado por mais duas horas com o A. Geralmente eles batem onde não aparece muito, cotovelo, cabeça, joelho. Depois disso os educadores nos deixam no cantinho da reflexão até que cicatrize". $O$ cantinho da reflexão é a cela de isolamento onde o adolescente fica suspenso de atividades e visitas.

J. falou sobre serem levados ao banheiro para receberem choque no pescoço pois, que só sentiam dor quando estavam molhados. G., o mais novo do grupo, 16 anos, testemunha: "Eu tenho marca de tiro, levei no abdômen de um policial e por pouco não fico sem andar". R. Mostra o maxilar deslocado devido agressões e relata: "Meu pai morreu uma semana depois que conheci ele". Depois desse evento, começou a praticar pequenos furtos e a utilizar drogas.

Denota-se ainda, a forma como os adolescentes ironizam as diversas fugas planejadas e realizadas por eles em plantões de educadores específicos com o intuito de prejudicá-los. O que nos chama a atenção é o fato de que as fugas acabam revelando algo que se repete na história desses sujeitos, pois eles, além acabar retornando para o mesmo lugar, são obrigados a cumprir por determinação judicial até o dobro do tempo estipulado a priori. Repetições que remetem a um retorno em circuito às mesmas celas mofadas e superlotadas daquela instituição.

Lacan (1954-55) refere que a repetição é introduzida pelo registro da linguagem a partir da função do símbolo. Trata-se da problemática da pergunta na ordem humana. Lacan (1964, P. 55) assevera ainda que nada pode ser pego, nem destruído, nem queimado, senão de maneira, como se diz, simbólica, in effigie, in absentia. Existiam muitos conteúdos a serem desvendados no ato repetitivo dos adolescentes de fugir e retornar àquela instituição e àquelas vivências destrutivas e autodestrutivas.

Freud, (1930), afirma que além da pulsão de conservação da vitalidade, que aproxima substâncias vivas, unificando-as em grupos cada vez maiores, agrupando sujeitos distantes, famílias, etnias, povos e nações numa grande unidade humana - 
ato civilizatório - existe algo antagônico, contrário, no qual se busca a dissolução desses grupos, a hostilidade de um contra todos e de todos contra um, e ainda uma espécie de retorno a um primórdio "inorgânico". O movimento da vida, bem como o da própria civilização se configura pela ação contraditória dessas forças.

Para possibilitar a construção da civilização, Freud (1930) refere que o ser humano abre mão de suas pulsões de destruição, mas a hostilidade primária não sucumbe por completo, assim a civilização é intermitentemente colocada em perigo diante de uma possível desintegração.

Lacan, (1960), questiona: o que afinal poderia ser a pulsão de destruição senão uma vontade de destruição direta? O autor (1954-55, p. 123) afirma: "No homem é a má forma que é prevalente. É na medida em que uma tarefa está inacabada que o sujeito volta a ela. É na medida em que um fracasso foi acerbo que o sujeito se lembra melhor dele". Freud no seu texto "Além do princípio do prazer" (1920) indica:

[...] Se o objetivo da vida fosse chegar a um estado nunca alcançado anteriormente, isso estaria em frontal contradição com a natureza conservadora das pulsões. Portanto, esse objetivo deve ser muito mais o de alcançar um estado antigo, um estado inicial, o qual algum dia o ser vivo deixou para trás e ao qual deseja retornar mesmo tendo de passar por todos os desvios tortuosos do desenvolvimento. Se pudermos admitir como um fato sem exceção que todo ser vivo morre, ou seja, retorna ao estado inorgânico devido a razões internas, então podemos dizer que: $O$ objetivo de toda vida é a morte, e remontando ao passado: O inanimado já existia antes do vivo (Freud, 1920, P. 161)

A pulsão de morte remete aqui a uma pulsão sem representação, a uma força que não possui contorno simbólico para escoar aos poucos, por pedaços, sem machucar de forma intensa o sujeito. Como nos lembra Clarice Lispector em "A paixão segundo G.H" (2009):

Uma forma contorna o caos, uma forma dá construção à substância amorfa - a visão de uma carne infinita é a visão dos loucos, mas se eu cortar a carne em pedaços e distribuí-los pelos dias e pelas fomes - então ela não será mais a perdição e a loucura: será de novo a vida humanizada (LISPECTOR , 2009, p. 12).

Aos poucos, percebeu-se que os adolescentes carregavam na carne as marcas e o preço pelos fragmentos de suas histórias. A dinamização das pulsões através das mediações simbólicas é importante para que o sujeito não passe ao ato. Para que ele não escoe a pulsão pelas vias da destruição e da autodestruição.

O possível funcionamento desses adolescentes pressupõe um tipo de escoamento como resto, dejeto, dispondo exclusivamente da posição de objeto. Sem 
braços para segurar, como os corpos no exercício que estimulava a confiança grupal. Um corpo/sujeito que cai sem uma rede de apoio que seja concreta e visível o suficiente para carregar, sustentar ou minimizar os prejuízos da queda. Trata-se do recorte de um objeto que cumpre com a função de dejeto e que de forma circular, através da compulsão à repetição, não cessa em tentar se inscrever.

\section{O CORPO DA INSTITUIÇÃO}

Além das dificuldades de manejo no grupo, a instituição realizou pequenos cortes à nossa intervenção. Além de suspender as atividades por duas semanas, a equipe técnica demonstrou insatisfação com a necessidade que o grupo colocou de facilitar a oficina sem a presença dos educadores (função semelhante à do agente penitenciário, vigilância e manutenção da ordem). No primeiro encontro, um educador aguardou a entrada de cada adolescente na sala e os empurrou com um tapa no pescoço. Um por um. Eles riram. O educador indicou: "Se comporta praí!", e riu.

Em ocasião de espera da retirada dos adolescentes das celas para iniciar as atividades, uma técnica aguardava conosco a chegada de todos os adolescentes na sala de grupo, alguns já se encontravam sentados no chão quando ela solicitou: "J., começa aí a flexão". Sem hesitar, J. começou a fazer exercícios de flexão com os braços no chão. Ela riu. A partir disso, entendeu-se porque era comum os adolescentes distraírem-se realizando exercícios de flexão. Seja nos intervalos entre um exercício e outro ou antes de iniciar a própria atividade. Goffman (1961, p. 21) identifica a institucionalização como um lento processo de mortificação do eu:

\footnotetext{
O novato chega ao estabelecimento com uma concepção de si mesmo que se tornou possível por algumas disposições sociais estáveis no seu mundo doméstico. Ao entrar, é imediatamente despido do apoio dado por tais disposições. Na linguagem exata de algumas de nossas mais antigas instituições totais, começa uma série de rebaixamentos, degradações, humilhações e profanações do eu. O seu eu é sistematicamente, embora muitas vezes não intencionalmente mortificado.
}

Corpos de 15, 17 anos com inscrições de tiro, facada, tortura e entre um intervalo ou outro, a exigência de contínuos exercícios de flexão pelos membros da instituição. R. fala:

"Tenho certeza que vocês enlouqueceriam se fossem lá pra baixo, se passassem um dia lá".

Foucault (2005, p. 132) afirma: "É dócil um corpo que pode ser submetido, que pode ser utilizado, que pode ser transformado e aperfeiçoado". De forma irônica, os

104 Psicanálise \& Barroco em revista | v.16, n. 01 | julho de 2018 
técnicos nomearam o nosso grupo como "aqueles que dançam". E as atividades continuaram sob vigilância constante dos educadores. Eles não estavam na sala, mas era recorrente abrirem e fecharem a porta pelo menos três vezes à cada encontro para observarem ou prezarem pela manutenção da segurança. Quando a música ressoava mais alto ou quando estávamos em silêncio, com frequência eles abriam, observavam pela fresta e em seguida fechavam a porta.

$\mathrm{Na}$ instituição, esses corpos eram destinados à flexões, opressões e agressões. Aparentemente não havia espaço para a palavra espontânea. Éramos, portanto, naquele corpo institucional, aqueles que dançavam. E aqueles que os convidavam a dançar. Eles ensaiavam ali versos para além das frases monossilábicas. O corpo é convidado aqui a também ser verbo, a conjugar movimentos, gestos, encontros e palavras.

\section{A Abertura dos Cadeados}

Eles dançaram até a exaustão, ritmos diferentes, tambores e percussão. Concluiu-se a atividade e nos sentamos, ficamos próximos, apenas olhando um para o outro. Os olhares já se encontravam e se demoravam. Abriu-se o espaço para a fala: C. indicou: "Eu estava viajando, não estava preso, quando estou aqui é como se não estivesse preso, parece que a gente esquece que depois vai voltar para a cela".

O abismo, aos poucos, começou a contornar um chão. No último encontro, eles foram os facilitadores e escolheram alguns exercícios que realizamos no decorrer da intervenção. Eles pegaram os óculos de grau de uma das facilitadoras e colocaram no novo facilitador, disseram: "Agora tu é a doutora!".

A primeira atividade se prolongou por mais de uma hora, de corpos rígidos e engessados, observou-se leveza, danças singulares, movimentos atemporais. O mais novo facilitador pegou uma fita que estava jogada na sala e explorou os movimentos do grupo. De uma fita que inicialmente soava de forma ameaçadora: "Qual é a tua fita?", passaram para outro tipo de fita, aquela que desliza entre os corpos e também dança, faz laço. Verifica-se aqui a torção da fita como o estabelecimento do laço transferencial.

Freud, (1916), nos lembra que é impossível ceder às exigências do paciente quando essas decorrem da transferência. Suportar sem indignação os hostis conteúdos transferênciais do paciente direcionados ao analista, permite mostrar que eles não se originam da situação atual, mas que o sujeito repete algo que the 
aconteceu anteriormente. A transferência, hostil ou amorosa, que parece representar ameaça ao tratamento, pode configurar-se, portanto, um de seus melhores instrumentos. Através dela, vários cadeados internos podem ser abertos.

Ao finalizar, todos deitam no chão. Olhos fechados. Aos poucos, abre-se espaço para as palavras, W. nos diz "Agora entendi o que é sentir, se permitir sentir" R. diz: "A cada oficina era como se um cadeado diferente fosse se abrindo no meu corpo, dentro de mim". R. diz: "Meu corpo tá preso, mas aqui a minha cabeça tá livre".

C. diz: "Antes havia uma mochila que pesava nas minhas costas e com as oficinas é como se ela fosse ficando mais leve". Interrogado sobre o que havia nessa mochila, ele nos disse: "vingança, ódio, tristeza", repetiu: "vingança, ódio, tristeza". N. indicou: "Eu não brigo mais na cela como antes, tem coisas que agora eu deixo pra lá. Só deixo pra lá". Os encontros aliviaram tensões e segundo eles, os conflitos nos alojamentos diminuíram, eles comentaram que relevavam muitas coisas que antes dos encontros não relevavam.

Freud, (1920), afirma que se nos detivermos nas forças que atuam na morfologia da matéria viva, podemos distinguir duas espécies de pulsões, as que visam conduzir a vida à morte e as que almejam a renovação de vida. A partir da cadeia significante, Lacan (1960) destaca que a cadeia de acontecimentos naturais está submetida, de forma implícita a uma pulsão dita de morte:

A pulsão de destruição põe em causa tudo o que existe, ela é também
vontade de criação a partir de nada, vontade de recomeço. A vida só está
presa ao simbólico de maneira despedaçada, decomposta. O próprio ser
humano se acha, em parte, fora da vida, ele participa do instinto de morte. E
só daí que ele pode abordar o registro de vida (Lacan, 1954-55, p. 127).

Por colocar em causa tudo o que existe, a pulsão de morte, despedaçada, decomposta está presa ao simbólico e é também vontade de criação a partir do nada. Os cadeados que aprisionam e deterioram também pode abrir-se para o registro da vida, com a mesma forma e na mesma intensidade.

R. finalizou o último encontro nos dizendo: "Isso aqui nos ajudou a tirar o mofo". Mofo era a expressão utilizada pelos adolescentes para falar sobre a superlotação, a comida inadequada, os colchões e as paredes inóspitas da instituição. Mas mofo também era o termo utilizado por eles para falar sobre o tempo de espera na prisão. Que tempo eles nos enunciam, afinal?

O tempo que nos é dado difere do tempo do sujeito. O tempo a que se propõe a psicanálise não é o tempo que conta, mensura ou calcula, conforme nos lembra 
Lacan em 1966 no texto "Tempo Lógico e a asserção da certeza antecipada". Tratase de um tempo que compõe um sujeito e o seu lugar na linguagem.

\begin{abstract}
Mostrar que a instância do tempo se apresenta de um modo diferente em cada um desses momentos é preservar-lhes a hierarquia, revelando neles uma descontinuidade tonal, essencial para seu valor. Mas, captar na modulação do tempo a própria função pela qual cada um desses momentos, na passagem para o seguinte, é reabsorvido, subsistindo apenas o último que os absorve, é restabelecer a sucessão real deles e compreender verdadeiramente sua gênese no movimento lógico. (LACAN, 1966, p. 204)
\end{abstract}

A partir da proposta de Lacan, indica-se que o tempo, além de linguagem, é espaço. Novarina (2003) refere que é na escuridão que a fala se produz, e pela linguagem que se dá o lugar do nascimento no espaço. É no tempo da música que o dançarino faz nascer o movimento e ocupa o espaço. "O tempo é indissociável do espaço" (Nominé, 2009, p. 51).

No fundo das celas, transborda a escuridão. Silêncio, abismo! A vida por uma fresta seja nas paredes, nas grades, no envelope, na música, no tempo. Eis o espaço que nos foi apresentado, corpos presos não apenas por celas e cadeados, mas pelas prisões alienantes de um tempo de espera.

O repertório padronizado compreende apenas o movimento da cabeça e dos olhos baixos, corpos retilíneos. O que se enuncia é um único e homogêneo corte de cabelo presente em todos: "Trata-se de um sofisma que nos dá pistas a respeito do que significa ter a vida decidida a partir de uma posição relativa aos outros" (Brandão Carreira, 2014, p. 252). Uma vida na repetição de seus cortes, de mofar em um único espaço e tempo diante da espera. O tempo de espera que se apresenta não é o tempo marcado pelo juiz, pela idade, o tempo em reclusão, mas o tempo inconsciente, o tempo é de outra ordem.

\footnotetext{
Portanto, essa temporalidade que se trata no acontecimento não tem nada a ver, nem com o tempo que passa, nem com o tempo da história; essa temporalidade diz respeito ao sujeito. Ela tem uma relação tão estreita com o sujeito, que poderíamos dizer que participa dos atributos do sujeito, no sentido gramatical do termo, porque esses acontecimentos aos quais 0 sujeito se esforça para voltar em seus sonhos são momentos que determinam aquilo que o sujeito foi, aquilo que ele se tornou, o que terá sido quando..., o que teria podido ser se... em resumo, trata-se de tentar simbolizar, de abarcar, da maneira mais próxima possível, esse momento, esse lapso de tempo, esse instante em que tudo se precipitou para tornar o sujeito aquilo que ele é (Nominé, 2009, p. 53).
}

O tempo é o tempo da linguagem, com suas pausas e continuidade. A linguagem tem ritmo, tem movimento. Como relata Julien (2001 apud Nominé, 2009), falar é o bastante para sustentar a existência do tempo. "O tempo é produzido pelo Psicanálise \& Barroco em revista | v.16, n. 01 | julho de $2018 \quad 107$ 
sujeito que fala. Este não deixa de ter relação com a língua que conjuga" (Nominé, 2009, p. 54).

Qual a temporalidade do mofo, colônia de fungos que cresce em objetos inertes, matéria orgânica e úmida que causa decomposição, destruição? Até que ponto o tempo desses adolescentes que convivem diariamente com o mofo de cada cela não pode ser deteriorado pelo tempo da espera? E o que cada um deles pode para além do abismo? Entre aqueles que estão marcados com a inscrição do picho, que possuem um corpo recortado como objeto de espancamento, esquecimento. Um grupo marcado para matar ou morrer. Como sair dessa inscrição?

Do fundo das gavetas de dentro de pastas e envelopes do fundo do silêncio encardido (...) esperam por um corpo de homem em que de novo se façam vivos" (GULLAR, 205, p. 594).

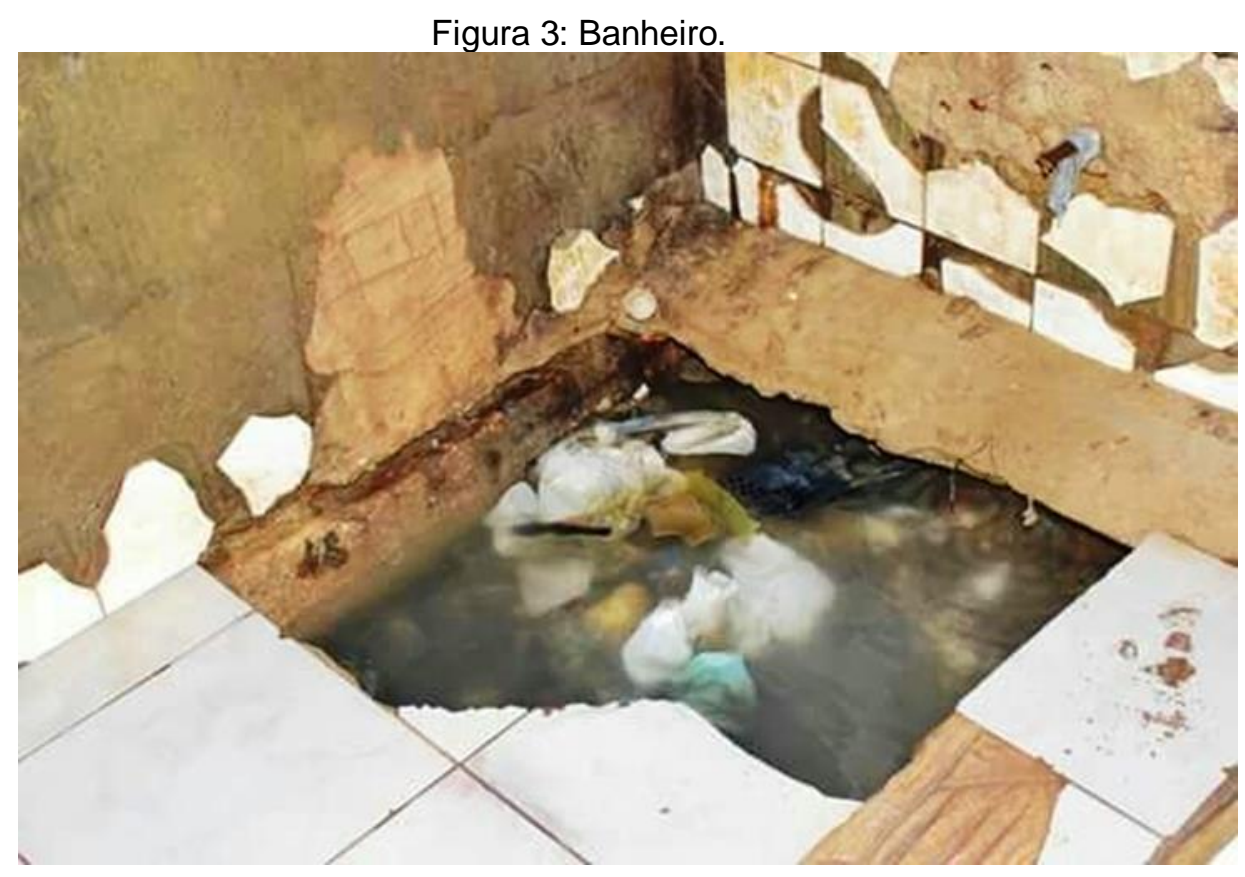

Fonte: Site jornalístico Seles Nafes (Disponível em: https://selesnafes.com/2018/02/). Foto: Tribunal de Justiça do Amapá 


\section{REFERÊNCIAS}

ABREU, C. (1977). Pedras de Calcutá: contos. São Paulo: Alfa Omega, 1977.

BOAL, A. (1979). 200 exercícios para o ator e o não-ator com vontade de dizer algo através do teatro. 2 Ed. Rio de Janeiro: Civilização brasileira, 1979.

BRANDÃO CARREIRA, L. (2014). Os tempos da escrita na obra de Clarice Lispector: No litoral entre literatura e psicanálise. Rio de Janeiro: Cia de Freud, 2014

FREUD, S. (1915) Pulsões e destinos da pulsão. In: Escritos sobre a psicologia do inconsciente, vol. 1. Trad. Luiz A. Hanns, L. A. Rio de Janeiro: Imago, 2004.

FREUD, S. (1916) Conferência XXVII “Transferência". Edição standard brasileira das obras psicológicas completas de Sigmund Freud, 16. Rio de Janeiro: Imago, 1996.

FREUD, S. (1920). Além do princípio do prazer. Edição standard brasileira das obras psicológicas completas de Sigmund Freud, vol. 18. Rio de Janeiro: Imago, 1996.

FREUD, S. (1930). O mal-estar na civilização. Edição standard brasileira das obras psicológicas completas de Sigmund Freud, vol. 21. Rio de Janeiro: Imago, 1996.

FOUCAULT, M. (1975). Vigiar e punir: nascimento da prisão. 30 Ed. Petrópolis: Vozes, 2005.

GARCIA-ROZA, L. (1995). Introdução à metapsicologia freudiana; v. 3: Artigos da metapsicologia - narcisismo, pulsão, recalque, inconsciente. Rio de Janeiro: Zahar, 1995.

GOFFMAN, E. (1961). Manicômios, prisões e conventos. São Paulo: Perspectiva, 1961.

GULLAR, F. (1976). Toda poesia. Rio de Janeiro: José Olympio, 2015

LACAN, J. (1954-1955). O seminário, livro 2: o eu na teoria de Freud e na técnica da psicanálise. Rio de Janeiro: Jorge Zahar.

LACAN, J. (1960). O seminário, livro 7: a ética da psicanálise. Rio de Janeiro: Jorge Zahar, 2008.

LACAN, J. (1962). Escritos. Rio de Janeiro: Jorge Zahar, 1998.

LACAN, J. (1964). O seminário, livro 11: os quatro conceitos fundamentais da psicanálise. Rio de Janeiro: Jorge Zahar, 1985.

LISPECTOR, C. (1964). A Paixão Segundo G.H. 15. ed. Rio de Janeiro: Francisco Alves, 1991.

LOWEN, A.; LOWEN, L. (1985) Exercícios de bioenergética: O caminho para uma saúde vibrante. 8 Ed. São Paulo: Ágora, 1985.

MAURANO, D. (2006). Para que serve a psicanálise? 2.ed. Rio de Janeiro: Jorge Zahar, 2006.

NOMINÉ, B. (2009). O tempo: um objeto lógico. Stylus, Rio de Janeiro, n. 18, p. 51-59, 2009.

NOVARINA, V. (1999). Diante da palavra. Rio de Janeiro: Sete Letras, 2003

SPOLIN, Viola (1963). Improvisação para o teatro. São Paulo: Perspectiva, 1963. 


\section{Falling Bodies: Adolescence, Prison and Psychoanalysis}

\section{ABSTRACT}

The objective of this work is to briefly present the experience report of a group intervention carried out during two months in 2017 with adolescents who comply with socio-educational measures and are in situations of deprivation of liberty in the city of Macapá-AP. It is indicated that such adolescents did not adapt easily to the activities proposed by the institution. In the space destined to the word, it was the space-time of the body that it stars them. From this specific address, body agitation, an intervention was elaborated through exercises of corporal expression with the objective of enabling a clinical device of listening. It is emphasized that not reducing psychoanalysis to the clinical space of the practice presupposes elaborating actions that use it as an ethical and theoretical reference in the social field. In addition to stories fragmented by traumatic experiences, it was possible to observe the manifestation of the circuit of compulsion to repetition and the death drive in the condition of imprisonment and social imprisonment that cross adolescents.

KEYWORDS: Death drive. Prison. Adolescence. Body. 


\section{Corps de Chute: Adolescence, Prison et Psychanalyse}

\section{RÉSUMÉ}

L'objectif est de travailler à travers cet exposé brièvement le rapport d'expérience d'une intervention de groupe détenu pendant deux mois en 2017 avec des adolescents qui rencontrent des mesures éducatives et sont dans une situation de privation de liberté dans la ville de Macapa-AP. II est indiqué que ces adolescents ne s'adaptaient pas facilement aux activités proposées par l'établissement. Dans l'espace destiné au mot, c'était l'espace-temps du corps qu'il les étoiles. A partir de cette adresse spécifique, le corps tremblant, a été élaboré une intervention à travers des exercices de langage corporel afin de permettre un dispositif d'écoute du clinicien. Il est souligné que ne pas réduire la psychanalyse à l'espace clinique de la pratique suppose d'élaborer des actions qui l'utilisent comme référence éthique et théorique dans le champ social. En plus des histoires fragmentées par des expériences traumatiques, il était possible d'observer la manifestation du circuit de la contrainte à la répétition et la pulsion de mort dans la condition d'emprisonnement et d'emprisonnement social qui traversent les adolescents.

MOTS-CLÉS: Pulsion de mort. Emprisonnement. L'adolescence corps. 
Corpos que Caem: Adolescência, Prisão e Psicanálise

Recebido em: 02-04-2018

Aprovado em: 22-04-2018

(C) 2018 Psicanálise \& Barroco em revista

http://www.seer.unirio.br/index.php/psicanalise-barroco/index

revista@psicanaliseebarroco.pro.br

Programa de Pós-Graduação em Memória Social — UNIRIO

Memória, Subjetividade e Criação

www.memoriasocial.pro.br/proposta-area.php

112 Psicanálise \& Barroco em revista | v.16, n. 01 | julho de 2018 